\title{
VINEYARD TREATMENTS PERFORMED WITH A RECYCLING TUNNEL SPRAYERS PROTOTYPE: PRELIMINARY ASSESSMENT
}

\author{
Alexandros Sotirios ANIFANTIS, Simone PASCUZZI, Francesco SANTORO \\ Department of Agricultural and Environmental Science (DiSAAT), University of Bari Aldo Moro, ITALY \\ E-mail of corresponding author: simone.pascuzzi@uniba.it
}

Keywords: pesticide application, tunnel sprayer, espalier trained vineyard, crop protection

\begin{abstract}
A towed single-row air-assisted tunnel recycling sprayer was developed by an Apulian Company in teamwork with the DISAAT of the University of Bari, aimed at meeting the requirements of the espaliers trained vineyards located in the Salento (Southern Apulia). Tests were then performed to assess the set up prototype with relation to the characteristic of the studied espalier trained vines. It was then necessary to point out technical solutions aimed at to reduce the size of the frame at the front of the machine, where is located the fixed shield. These actions made the prototype more suitable to the characteristics of the studied vineyards and the defined technical solutions can be considered generalizable for the tunnel sprayers employed in such trained vines of the Salento. Further tests are necessary to better assess the performance of the prototype also in different phenological stages.
\end{abstract}

\section{INTRODUCTION}

Apulia is Southern Italy's leading region for wine grape production, with an addressed area of about $8.6 \times 10^{4}$ ha and a yield of about $10.1 \times 10^{8} \mathrm{~kg}$ (ISTAT, 2014). In Apulia, the most common vine training systems used for wine grape are the espaliers with Guyot pruning system or simple/double side cordon and the "pergolato" or "tendone", an overhead canopy supported by a trellis system, also particularly employed for table grapes vines in the Region. Protection of these vineyards entail several treatments from April to November and the sprayers generally are conventional air-assisted sprayers and pneumatic sprayers, sometimes fitted with electrostatic device (Pascuzzi and Cerruto, 2015b; Pascuzzi, 2013).

A peculiar characteristic of the espalier Apulian vines, due above all to the propitious climatic conditions, is the significant development of the vegetation during the final growth stages, which at time may produce some impediments. With regard to the espaliers vines located in the Salento (Southern Apulia), the foliar development becomes considerable from the fruit set growth stage on, so producing a significant reduction of the size of the inter-row, which compromises the transit of the machines (Giametta et al., 2015). These vineyards are suitable for the employment of the recycling tunnel sprayers, which have long been recognised as an important tool to greatly reduce both soil contamination and airborne drift (Pergher et al., 2013). These machines meet also the requirements of the European Regulations concerning sustainable use of pesticides (Directive 2009/128/EC), by recovering and recycling most of the spray fraction that has not been retained by the canopy (Balsari et al., 2007).

Based on a research funded by the European Fund for Apulian Regional Development (PON02 00657-00186-2866121 Project (ECO_P4)), within a research program of the Ministry of Education, University and Research and the Ministry of Economic Development, an ad hoc towed single-row air-assisted tunnel recycling sprayer was developed by an Apulian Company in teamwork with the DiSAAT of the University of Bari, aimed at meeting the requirements of the espaliers trained vineyards located in the Salento (Southern Apulia). The objective of the present research was to assess the 
performance of this prototype with relation to the characteristic of the espalier trained vines of the Salento, evaluating the spray deposition on the foliage at different locations of the vine canopy.

\section{MATERIALS AND METHODS}

\section{The tunnel sprayer}

The towed air-blast tunnel sprayer (Fig.1c), manufactured by the Company Maggio with the collaboration of the DiSAAT, is specifically designed for pesticide application in espalier vineyards of the Salento. The machine is built by adopting a galvanized steel frame on which the following elements are arranged: the $1000 \mathrm{~L}$ tank for the mixture; the axial fan; the pump unit with its connections; valves to control and limit pressure and to control flow volume; positional hydraulic and mechanical servo-mechanisms for the motion of the shields; the piping for conveying the air flow produced by the fan to the two shields of the tunnel. One of the shield of the tunnel is rigidly connected to the frame, while the other one can slide horizontally, allowing adjustment of the distance between the shields. The machine is equipped with sensors connected to the control unit, so allowing to evaluate in real time the operating parameters: nozzle flow rate, operating pressure, sprayer velocity, volume rate.
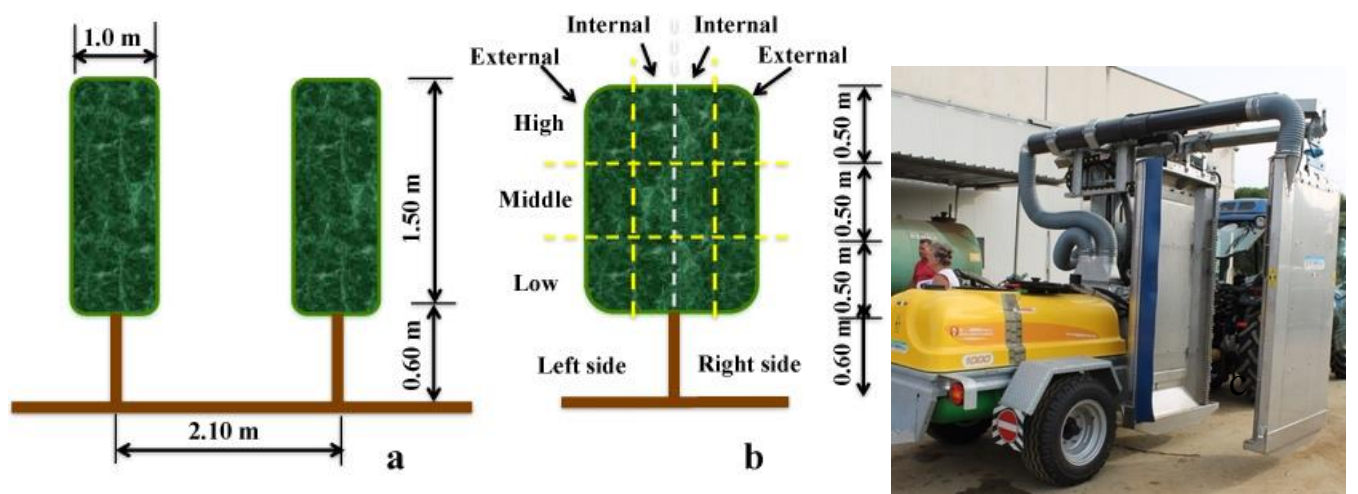

Figure 1. a: Scheme of the vineyard; b: Partition of the canopy into six zones; c: Towed air blast singlerow tunnel sprayer built by Maggio Company.

\section{The vineyard, spraying tests, foliar sampling and data analysis}

Experimental spraying tests were carried out in a espalier vineyard ("Falanghina" variety") located on a farm in the territory of Cellino San Marco (Brindisi province Apulia - Italy). The vines were planted with a layout of $2.1 \mathrm{~m} \times 1.0 \mathrm{~m}$, giving a density of 4760 plants/ha (Figure 1a). Foliar deposits were assessed during berry touch phenological stage by spraying a mixture containing a food dye tracer (yellow tartrazine, Sigma Chemical) at a concentration of $4 \mathrm{~g} \mathrm{~L}^{-1}$ and measuring the volume of mixture deposited per unity of leaf surface $\left(\mu \mathrm{L} \mathrm{cm}^{-2}\right)$. The tests were carried out by passing with the sprayer in an inter-row with the shields of tunnel straddling a row; spraying then the right and left sides of the row. Foliar sampling and deposit assessment were then carried out in the row. Particularly, foliar spray deposition was measured in different canopy locations, obtained considering the following divisions (Figure 1b): a) the vertical plane of mirror symmetry, which partitioned the canopy of the row into "Right side" and "Left side" with respect to the direction of the sprayer advancement; b) the vertical planes crossing the centre-line of the Right and Left sides, respectively, so producing the sectors "Internal" and "External"; c) the horizontal planes located respectively at $1.10 \mathrm{~m}$ and $1.60 \mathrm{~m}$ from the 
ground, which finally partitioned the canopy into three levels: "Low", "Middle" and "High". Therefore, twelve sampling zones were defined on each sample tree to measure foliar deposits (Figure 1b). The following operative parameters of the prototype were considered: a) speed of $5 \mathrm{~km} \mathrm{~h}^{-1}$, typically adopted by the farmer to carry out the treatments; b) volume rate of $600 \mathrm{~L} \mathrm{ha}^{-1}$; c) working nozzles $6+6$, located at the middle and lower parts of the shields; d) nozzles type Albuz ATR $80^{\circ}$, pressure $0.75 \mathrm{MPa}$. The test was replicated three times according to a randomized block design and 4 leaves were randomly sampled in each zone, totalling 48 leaves per replication, and then 144 leaves per treatment. Each leaf was placed in a Petri dish, and the unitary deposit was measured in the laboratory by applying a spectrophotometric technique (Pascuzzi and Cerruto, 2015a). Deposits were statistically analysed by applying the factorial analysis of variance (ANOVA), using the open source software R (R Core Team, 2012).

\section{RESULTS AND DISCUSSION}

The results of the test carried out are summarized in Figure 2, which shows the average deposits obtained respectively for the considered sides ("Right" and "Left"), levels ("Low", "Middle", "High") and sectors ("Internal", "External"). The difference between the deposits registered on the left and right side of the row is not statistically significant. Conversely, the obtained values $0.46 \mu \mathrm{L} \mathrm{cm}^{-2}$ ("Left side") and $0.50 \mu \mathrm{L} \mathrm{cm}^{-2}$ ("Right side") highlight a uniform distribution of the mixture on both sides of the row. Furthermore, about the same amount of mixture was distributed at the "Low" $(0.61 \mu \mathrm{L}$ $\left.\mathrm{cm}^{-2}\right)$ and "Middle" $\left(0.62 \mu \mathrm{L} \mathrm{cm}^{-2}\right)$ levels of the row, whereas the deposit registered at the "High" $\left(0.20 \mu \mathrm{L} \mathrm{cm}^{-2}\right)$ level is much lower and is approximately $1 / 3$ of those ones of the other levels. This statistically significant difference is probably due to the absence of working nozzles corresponding the high level of the shields. Finally, the difference of the average registered deposits between the sectors "Internal" $\left(0.29 \mu \mathrm{L} \mathrm{cm}^{-2}\right)$ and "External" $\left(0.68 \mu \mathrm{L} \mathrm{cm}^{-2}\right)$ is statistically significant.

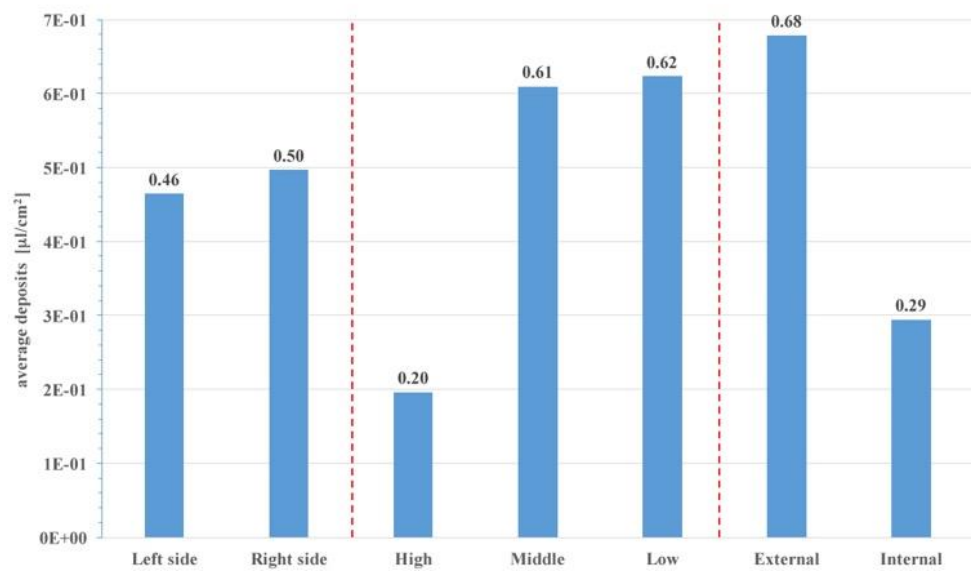

Figure 2. Average deposits concerning the considered partitions of the canopy

Altogether the results highlight that the prototype enables a good distribution of the spray on the vegetation, point out some problems. Really, starting from the phenological stage of fruit set, when the development of the canopy becomes considerable, the sizes of the machine are unacceptable, because in these conditions a proper homogeneous distribution of the product on vegetation is thwarted and the shields of the tunnel strip on the vegetation, even if their distance was the maximum allowed. Therefore, it was necessary to set up technical solutions aimed at to reduce the size of the frame at the front of the 
machine, where is located the fixed shield and to increase the largest between the shields. According to these actions, the prototype is become more suitable to the characteristics of the studied vineyards of the Salento.

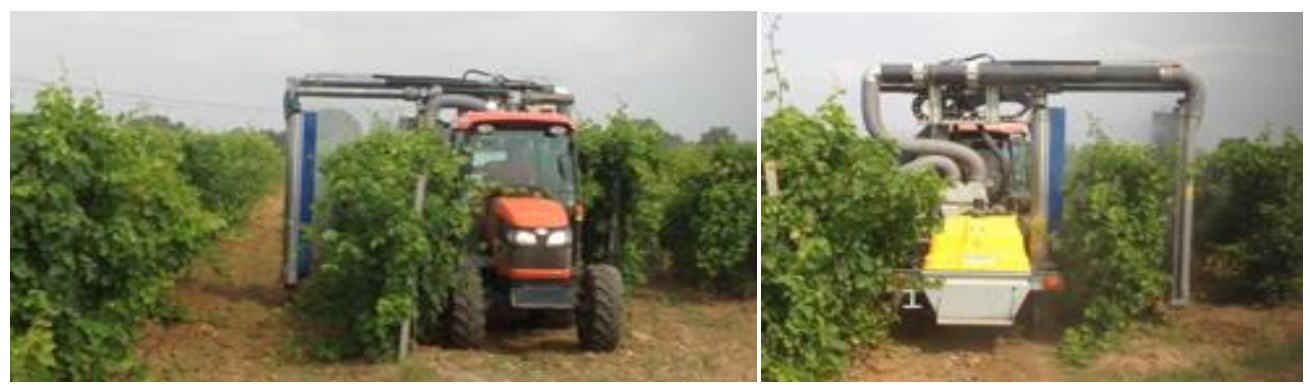

Figure 3. Modified prototype in a full leaf stage vineyard of Salento: the machine moves easily in the short passage between the rows tree; the shields have sufficient space for transversal settings.

\section{CONCLUSIONS}

The exclusive characteristics of the espalier training vine system of the Salento is the significant development of the vegetation during the final growth stages, which creates a striking reduction of the size of the inter-row. An ad hoc towed single-row air-assisted tunnel recycling sprayer was developed to meet the requirements of these vines and tests were carried out for assessing its performance. According to the results of the experimentation, it was necessary to point out technical solutions aimed at to reduce the size of the frame at the front of the machine, where is located the fixed shield, and to raise the maximum allowed distance between the shields (Figure 3). These actions made the prototype more suitable to the characteristics of the studied vineyards and the defined technical solutions may be considered generalizable for the tunnel sprayers employed in such trained vines of the Salento.

\section{REFERENCES}

Balsari, P., Oggero, G., Marucco, P., (2007). Proposal of a guide for sprayers calibration. Proceedings of SPISE Workshop. Straelen, Germany, 10-1 2April 2007.

Directive 2009/128/EC, available from: http://eur-lex.europa.eu/LexUriServ/

LexUriServ.do? uri=OJ:L:2009:309:0 071:0086:en:PDF

Giametta F., Brunetti L., Romaniello R., Bianchi B. (2015). Ecological Efficiency Assessment of a Specific Machine for Distribution of Pesticides in Vineyards of Apulian Region. WSEAS Transactions on Environment and Development. ISSN / E-ISSN: 1790-5079 /2224-3496, Volume 11, 2015, Art. \#24, pp. 219-227.

ISTAT Italian Central Statistics Institute (2014) http://agri.istat.it/jsp/dawinci.jsp?q= plC260000010000012000\&an=2014\&ig=1\&ct=604\&id=15A|21A $73 \mathrm{~A}$

Pascuzzi S. (2013). The effects of the forward speed and air volume of an air-assisted sprayer on spray deposition in «tendone» trained vineyard». J. Agric. Eng., XLIV: e18, 125-132.

Pascuzzi S., Cerruto E. (2015a). Spray deposition in "tendone" vineyards when using a pneumatic electrostatic sprayer. Crop Prot. 68, 1-15.

Pascuzzi S., Cerruto E. (2015b). An innovative pneumatic electrostatic sprayer useful for tendone vineyards. J. Agric. Eng., XLVI:458, 123-127.

Pergher, G., Gubiani R., Cividino S.R.S., Dell'Antonia D., Lagazio C. (2013). Assessment of spray deposition and recycling rate in the vineyard from a new type of air-assisted tunnel sprayer. Crop Protection 45: 6-14.

R Core Team, (2012). R: A language and environment for statistical computing. $R$ Foundation for Statistical Computing, Vienna, Austria. ISBN 3-900051-07-0, URL http://www.R-project.org/. 